CLINICAL STUDY

\title{
Maternal compound $W$ serial measurements for the management of fetal hypothyroidsm
}

\author{
Donatella Cortelazzi ${ }^{1}$, Paola S Morpurgo ${ }^{1}$, Paola Zamperini ${ }^{2}$, Delbert A Fisher ${ }^{3}$, Paolo Beck-Peccoz ${ }^{1}$ \\ and Sing-Yung $\mathrm{Wu}^{4}$ \\ ${ }^{1}$ Institutes of Endocrine Sciences and ${ }^{2}$ Biomedical Sciences, University of Milan, Ospedale Maggiore IRCCS, Istituto Clinico Humanitas \\ and San Paolo Hospital, Milan, Italy, ${ }^{3}$ Perinatal Laboratory, Harbor-UCLA Medical Center, Torrance, California 90509, USA and \\ ${ }^{4}$ Nuclear Medicine and Medical Services, Veterans Administration Medical Center, Long Beach, California 90822, USA \\ (Correspondence should be addressed to P Beck-Peccoz, Istituto Clinico Humanitas, Via Manzoni, 56, 20089 Rozzano, MI, Italy; \\ Email:paolo.beck-peccoz@humanitas.it)
}

\begin{abstract}
Objective: The diagnosis of fetal hypothyroidism is based at present on measurements of TSH and free thyroxine (FT4) in fetal blood samples obtained by cordocentesis. The measurement of maternal serum and urinary concentrations of compound $\mathrm{W}$, immunologically similar to but chromatographically distinct from diiodothyronine sulfate (T2S), has been advocated as a new possible marker for fetal hypothyroidism.

Design: In this paper, we measured serum compound W levels in 84 pregnant women, 20 with and 64 without thyroid disorders before and during specific treatment. Compound $W$ was also assessed in fetal blood obtained by cordocentesis from 49 normal fetuses and 4 fetuses with suspected hypothyroidism due to transplacental passage of propylthiouracil (PTU). Compound $\mathrm{W}$ levels were measured by T2S RIA in maternal and fetal serum. To assess the possible usefulness of 3,5,3'-triiodothyroacetic acid (TRIAC) for therapy of fetal hypothyroidism we evaluated the transplacental passage of TRIAC by administering the drug to four pregnant women before therapeutic abortion.

Results: In normal pregnancies, both maternal and fetal compound W levels increased progressively during gestation with a significant direct correlation $(P<0.001$, in both mothers and fetuses). Moreover, a significant positive correlation was observed between fetal compound W and fetal FT4 values $(P<0.005)$, whereas no correlation was observed between maternal serum compound $W$ and maternal FT4 in either euthyroid or hyperthyroid women, suggesting the fetal origin of compound W. The hypothyroid fetuses of PTU-treated mothers showed low compound W levels, and maternal compound $W$ values were in the low normal range and did not show the typical increase during progression of gestation. A significant increase of maternal compound $\mathrm{W}$ was observed when the PTU dose was reduced. TRIAC was documented to cross the placental barrier and the treatment of a hyperthyroid pregnant woman on PTU caused the high fetal TSH levels and goiter to normalize. Conclusions: Serial measurements of 3,3'-T2S crossreactive materials (compound W and 3,3'-diiodothyroacetic acid sulfate) in maternal blood and the administration of TRIAC to the mother may represent a useful and safe alternative to invasive techniques for the diagnosis and therapy of fetal hypothyroidism.
\end{abstract}

European Journal of Endocrinology 141 570-578

\section{Introduction}

Contrary to what occurs in thyroid hormone metabolism of the adult, the sulfation pathway in the fetus plays an important role, as the levels of sulfated iodothyronines are much higher in the fetus than in the adult (1), including pregnant women (2). The reduced clearance secondary to relatively low type I 5 -monodeiodinase activity in fetal tissue and the high fetal production rate account for these high levels (3). However, the sulfated iodothyronines thyroxine (T4) and triiodothyronine (T3) cannot be used as parameters of fetal thyroid function based on maternal sampling as the levels are too low in maternal serum and no correlation has been found between fetal and maternal concentrations (4). Interestingly, in recent studies a new iodothyronine sulfate analog, named compound W, has been described (5). Compound W, which is immunologically similar to diiodothyronine sulfate (T2S), but does not co-chromatograph with synthetic T2S by HPLC, has been reported to be present in maternal serum (5) and maternal urine (6) and to increase during pregnancy 
in parallel with the progressive maturation of fetal thyroid function (7). These observations and the finding of disappearance of this material after parturition strongly suggest the fetal origin of compound W. The chemical structure of compound $W$ is not yet clear, but the possibility that it is produced by the fetus suggests that compound $\mathrm{W}$ could be considered a potential marker of fetal thyroid function. The measurement of fetal thyroid hormones in amniotic fluid is not a reliable method of detecting fetal hypothyroidism because the hormone levels reflect maternal as well as fetal thyroid function (8-11). Thus, the diagnosis of fetal hypothyroidism depends on thyrotropin (TSH) and free T4 (FT4) measurements in fetal blood samples obtained by cordocentesis. However, this technique is associated with a $1 \%$ fetal loss and the risk is compounded for hyperthyroidism-complicated pregnancy when more than one cordocentesis may be necessary to evaluate fetal well-being (12).

Fetal thyroid function may be impaired by the transplacental passage of anti-thyroid drugs (13) and fetal hypothyroidism carries the risk of neurological damage despite early neonatal treatment (14). A recent report suggests that 3,5,3'-triiodothyroacetic acid (TRIAC) given to propylthiouracil (PTU)-treated hyperthyroid mothers might be useful in the treatment of fetal goiter (15). TRIAC is a thyroid hormone analog that results from the oxidative deamination and decarboxylation of the alanine side-chain of $\mathrm{T} 3$ and is present in low concentration in normal subjects (16). TRIAC binds to thyroid hormone receptors with an affinity higher than that of T3 (17) but with shorter duration of nuclear occupancy (18) and will reduce TSH concentrations with less pronounced thyromimetic effects at the peripheral tissue level (19). The present study was undertaken in order to investigate both the utility of compound $\mathrm{W}$ as a maternal serum marker of fetal hypothyroidism, and the application of TRIAC for treatment of fetal hypothyroidism.

\section{Materials and methods}

\section{Subjects}

Samples from 64 normal pregnant women and 49 normal fetuses were obtained at gestational ages ranging from 14 to 40 weeks. Fetal blood was collected by cordocentesis carried out for rapid karyotyping and diagnosis of infection or hematological disorders or during elective cesarian section. The normal fetuses included in this study were judged healthy by measurements of blood oxygenation and acid-base balance status conducted at the time of fetal sampling. Definitive confirmation of their healthy state was achieved by clinical examination at birth and during at least 2 months of follow-up. Twenty pregnant women with thyroid disorders were monitored monthly with obstetric ultrasonography, evaluation of thyroid function and measurement of serum compound W levels. Among them, eight patients were hypothyroid; two others with non-toxic nodular goiter were started or continued on L-T4 therapy in substitutive or TSH-suppressive doses. Ten patients were hyperthyroid and treated with PTU. Fetal blood samples were collected by cordocentesis carried out for suspected fetal hypothyroidism in four of these women and all four fetuses were found to be hypothyroid. One other hyperthyroid patient was treated with combined PTU and TRIAC (orally at the dose of $2.1-2.8 \mathrm{mg} /$ day). The study protocol was approved by the Ethical Committee of our Institutions, and informed consent was obtained from each woman.

\section{Cordocentesis}

Fetal blood was sampled via cordocentesis using a 22 gauge heparinized needle guided by ultrasonography and under aseptic conditions. The reliability of fetal sampling was assessed by analysis of red cell volume with a Coulter counter and Kleihauer smears were prepared to confirm the fetal source of blood $(8,20)$.

\section{Transplacental passage of TRIAC}

Six pregnant women (20-25 weeks of gestation) electing therapeutic abortion for severe fetal malformations gave their informed consent to the study. TRIAC $(3.5 \mathrm{mg}$ orally) was administered to four women, whereas T3 ( $200 \mu \mathrm{g}$ orally) was given to the other two; $46-76 \mathrm{~min}$ after TRIAC or T3 administration, fetal blood samples were obtained by cordocentesis carried out before the abortive operations. Serum concentrations of the analog were quantified utilizing a fluoroimmunoassay method for free T3 (FT3) measurement which shows 100\% crossreactivity with TRIAC. Placental function was documented to be normal in all women based on fetal heart rate, umbilical-artery blood flow and blood gas levels (21).

\section{TSH and free thyroid hormone measurements}

Circulating levels of TSH, FT4 and FT3 were measured by ultrasensitive immunofluorometric assay and fluoroimmunoassay, using Delfia techniques (Pharmacia, Milan, Italy). The crossreactivity of TRIAC in the FT3 assay was $100 \%$.

\section{T2S RIA}

The T2S RIA procedure employed in this study was described previously (5). In brief, serum samples were extracted with 3 volumes 63\% (final) ethanol before assay. Final values of T2S or compound W (expressed as T2S-equivalence) were not corrected for recovery. 3,3'T2S and ${ }^{125} \mathrm{I}-3,3^{\prime}-\mathrm{T} 2 \mathrm{~S}$ were prepared by the method of Eelkman-Rooda and co-workers (21). T2S was further purified and quantitatively recovered by reverse phase 
HPLC with a preparative column. The RIA employed an anti-L-3,3'-T2S antibody obtained from rabbits immunized with L-T2S BSA conjugate. The lower limit of detection of the assay was $5 \mathrm{ng} / \mathrm{dl}$. The results are expressed as T2S-equivalent in $\mathrm{ng} / \mathrm{dl}$.

\section{Identification of compound $W$}

T2S immunoreactivity was studied in maternal and fetal serum. Greater than $0.5 \mathrm{ml}$ was extracted with 2 volumes $95 \%$ ethanol and subsequently lyophilized. The dried extracts were dissolved in $1-2 \mathrm{ml} \mathrm{H}_{2} \mathrm{O}$ and purified using an LH-20 column as previously described (5). One milliliter of the solubilized extract was applied to a small LH-20 column (bed volume, $1.2 \mathrm{ml}$ ) equilibrated in $0.1 \mathrm{~mol} / \mathrm{l} \mathrm{HCl}$. After rinsing the column with $4 \mathrm{ml}$ $0.1 \mathrm{~mol} / \mathrm{l} \mathrm{HCl}$, the ensuing seven $\mathrm{H}_{2} \mathrm{O}$ eluant fractions were collected and lyophilized. The dried fractions were dissolved in $500 \mu \mathrm{l} 0.025 \mathrm{~mol} / \mathrm{l} \mathrm{NaOH}, 200 \mu \mathrm{l}$ aliquots were applied to an HPLC Bondapak C18 column (Waters, Millipore Corporation, Millford, MD, USA), and eluates were developed isocratically with a mixture of acetonitrile and $0.02 \mathrm{~mol} / \mathrm{l}$ ammonium acetate, $\mathrm{pH} 4.0$ (22:78 $\mathrm{v} / \mathrm{v}$ ) at a flow rate of $2 \mathrm{ml} / \mathrm{min}$. One-milliliter eluent fractions was collected, and $50 \mu \mathrm{l}$ of these aliquots were subjected to T2S RIA. Radioactive or non-radioactive T2S-supplemented serum extracts from non-pregnant women were used to identify the T2S and compound W peaks.

One milliliter of $63 \%$ ethanol serum extract was mixed with $1 \mathrm{ml} 1.0 \mathrm{~mol} / \mathrm{l} \mathrm{HCl}$, followed by heating at $80^{\circ} \mathrm{C}$ for $1 \mathrm{~h}$ to hydrolyze sulfated iodothyronines, as described by Mol \& Visser (22). After the addition of $1 \mathrm{ml} 1 \mathrm{~mol} / \mathrm{l} \mathrm{NaOH}$, the concentration of 3,3'-diiodothyronine (T2) was measured in duplicate $300 \mu \mathrm{l}$ aliquots of the resulting mixture by specific RIA (23). On hot acid digestion of serum extracts, less than $10 \%$ of $\mathrm{T} 2 \mathrm{~S}$ immunoreactivity was recovered as $3,3^{\prime}-\mathrm{T} 2$.

\section{Identification of 3,3'-diiodothyroacetic acid sulfate (DIACS)}

In serum extracts from the TRIAC-treated pregnant women, a new T2S-crossreactive peak, in addition to the compound W peak, was identified by HPLC with a $\mu$ Bondapak C18 column eluted isocratically with acetonitrile and $0.02 \mathrm{~mol} / \mathrm{l}$ ammonium acetate, $\mathrm{pH} 4.0$ $(22: 78 \mathrm{v} / \mathrm{v})(5)$. This new peak of activity eluted $35 \mathrm{~min}$ was later than the peak of compound $W$. This peak was not found in pregnant women who were not treated with TRIAC. ${ }^{125}$ I-3,3'-DIACS, which was synthesized from 3-monoiodothyroacetic acid (a gift from Dr Hans J Cahnmann, Bethesda, MD, USA), was found to cochromatograph with the T2S-crossreactive peak. The extent of crossreactivity of 3,3'-DIACS and T2S is not known due to a lack of stable and pure 3,3'-DIACS for use in the T2S RIA. The HPLC identification of 3,3'DIACS in fetal serum was not made due to inadequate sample volumes.

\section{Statistical analysis}

Data are expressed as mean \pm s.D. Student's unpaired $t$-test was used to assess differences among the various groups. Differences were considered statistically significant at $P<0.05$. Simple linear regression analysis was used to test the correlation during different gestational ages.

\section{Results}

\section{Compound $W$ concentrations in fetal and maternal sera}

Serum compound $\mathrm{W}$ concentrations in 49 normal fetuses and in 64 normal pregnant women increased progressively throughout gestation as shown in Table 1 and Fig. 1.

Figure 2 shows the significant positive correlations between fetal compound $\mathrm{W}$ and fetal FT4 $(n=29, P<$ $0.003)$, and maternal compound $W(n=42, P<$ 0.0001). No significant correlations were observed between maternal compound $\mathrm{W}$ and fetal FT4 or compound W and fetal TSH. Moreover, no significant correlation was seen between maternal compound W and maternal FT4.

Figure 3 shows the correlation of fetal and maternal serum compound $W$ values and maternal urine

Table 1 Ranges and mean of fetal and maternal compound W (ng/dl) at various gestational ages in normal pregnancies.

\begin{tabular}{lcccc}
\hline & $\mathbf{1 4 - 2 0}$ weeks & $\mathbf{2 1 - 2 6}$ weeks & 27-36 weeks & 37-40 weeks \\
\hline Fetuses & & & & \\
No. samples & 7 & 24 & 13 & 5 \\
Range & $22-177$ & $31-180$ & $94-260$ & $124-200$ \\
Mean \pm S.D. & $70 \pm 56$ & $98 \pm 34$ & $138 \pm 48$ & $158 \pm 27$ \\
Mothers & & & & \\
No. samples & 10 & 28 & 21 & 5 \\
Range & $27-138$ & $23-159$ & $53-164$ & $84-194$ \\
Mean \pm S.D. & $54 \pm 31$ & $67 \pm 29$ & $90 \pm 32$ & $108 \pm 50$ \\
\hline
\end{tabular}



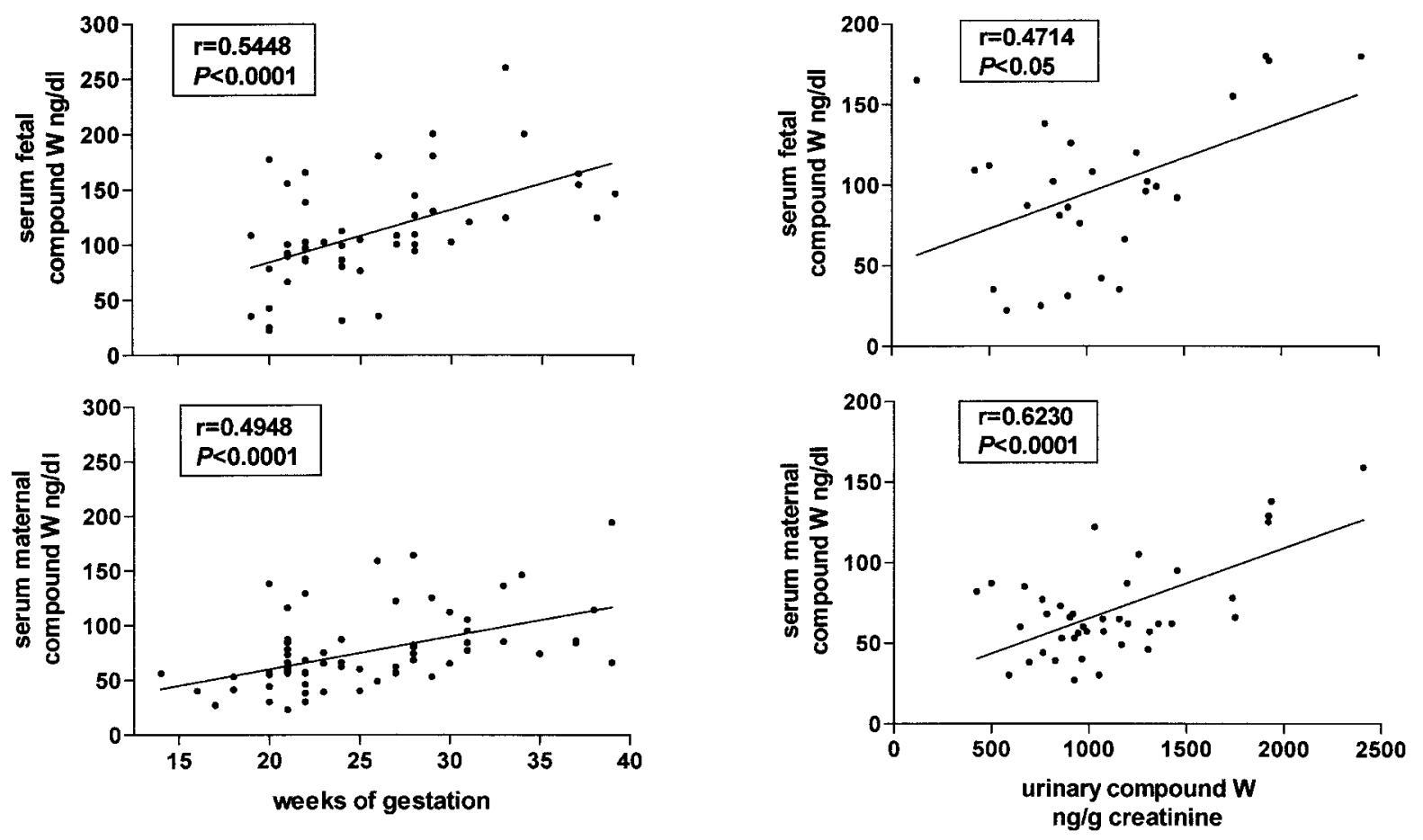

Figure 1 Compound W levels in 49 fetal and 64 maternal sera: correlation with the weeks of gestation.
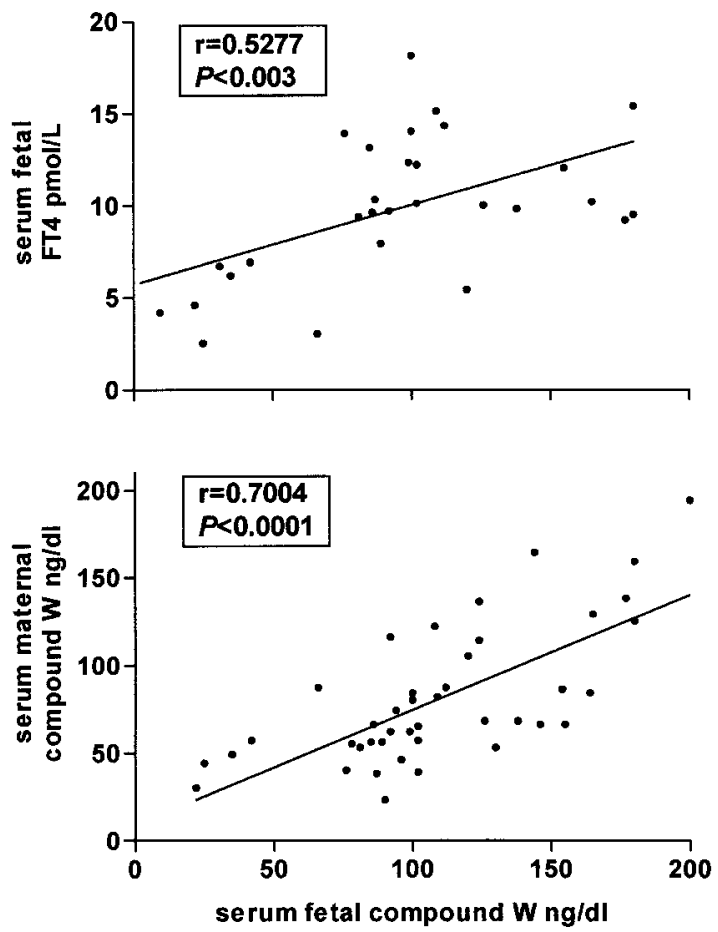

Figure 2 Compound $\mathrm{W}$ levels in fetal serum: correlation with serum fetal FT4 $(n=29)$ and maternal compound W $(n=42)$.

Figure 3 Compound $\mathrm{W}$ levels in urine: correlation with serum fetal compound $\mathrm{W}(n=27)$ and serum maternal compound $\mathrm{W}(n=40)$.

compound $\mathrm{W}(n=27, P<0.05$ and $n=39, P<0.001$ respectively).

Compound $\mathrm{W}$ concentrations in pregnant women with thyroid disorders were within the normal range for gestational age, both before and during specific treatment (Fig. 4). In fact, in eight hypothyroid mothers treated with L-T4, serum compound $\mathrm{W}$ increased progressively during gestation and levels were in the normal range for gestational age (Fig. 4). Similar data were found in two women treated with TSH-suppressive doses of L-T4 for non-toxic goiter (Fig. 4). The range of compound $\mathrm{W}$ levels in ten hyperthyroid mothers was similar to values in the euthyroid women both before and during PTU treatment (Figs 1 and 4).

Figure 5 shows the trend of compound $\mathrm{W}$ during gestation, assessed by serial measurements in three normal pregnant women (followed for suspected hyperthyroidism) (Fig. 5A), in six hypothyroid women treated with substitutive doses of L-T4 (Fig. 5B) and in four hyperthyroid women treated with PTU (Fig. 5C). In the last four patients, compound $\mathrm{W}$, though in the normal range, did not increase during the progression of gestation. Clinical and biochemical features of these women precluded reducing the therapy dose to less than $100 \mathrm{mg} /$ day of PTU. At 14 weeks of gestation, one patient discontinued PTU therapy for unknown reasons. As shown in Fig. 5C (open triangle), compound W levels increased remarkably and declined when PTU therapy was reestablished. Unfortunately, these hyperthyroid women did not give consent to cordocentesis and 


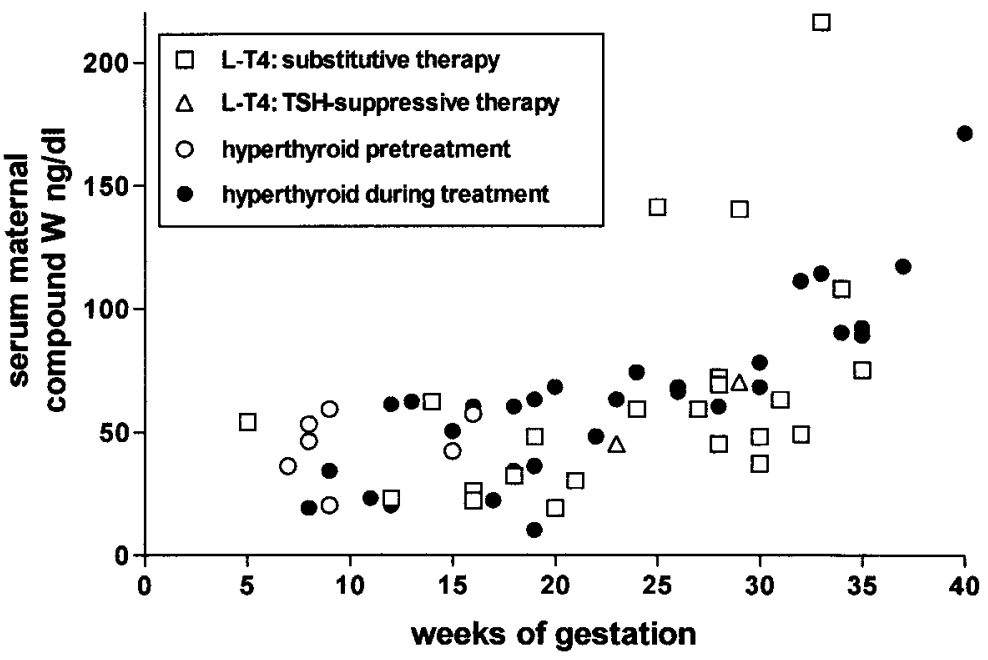

Figure 4 Compound W levels in pregnant women affected by thyroid disorders before and during specific treatment are in the normal range for gestational age.
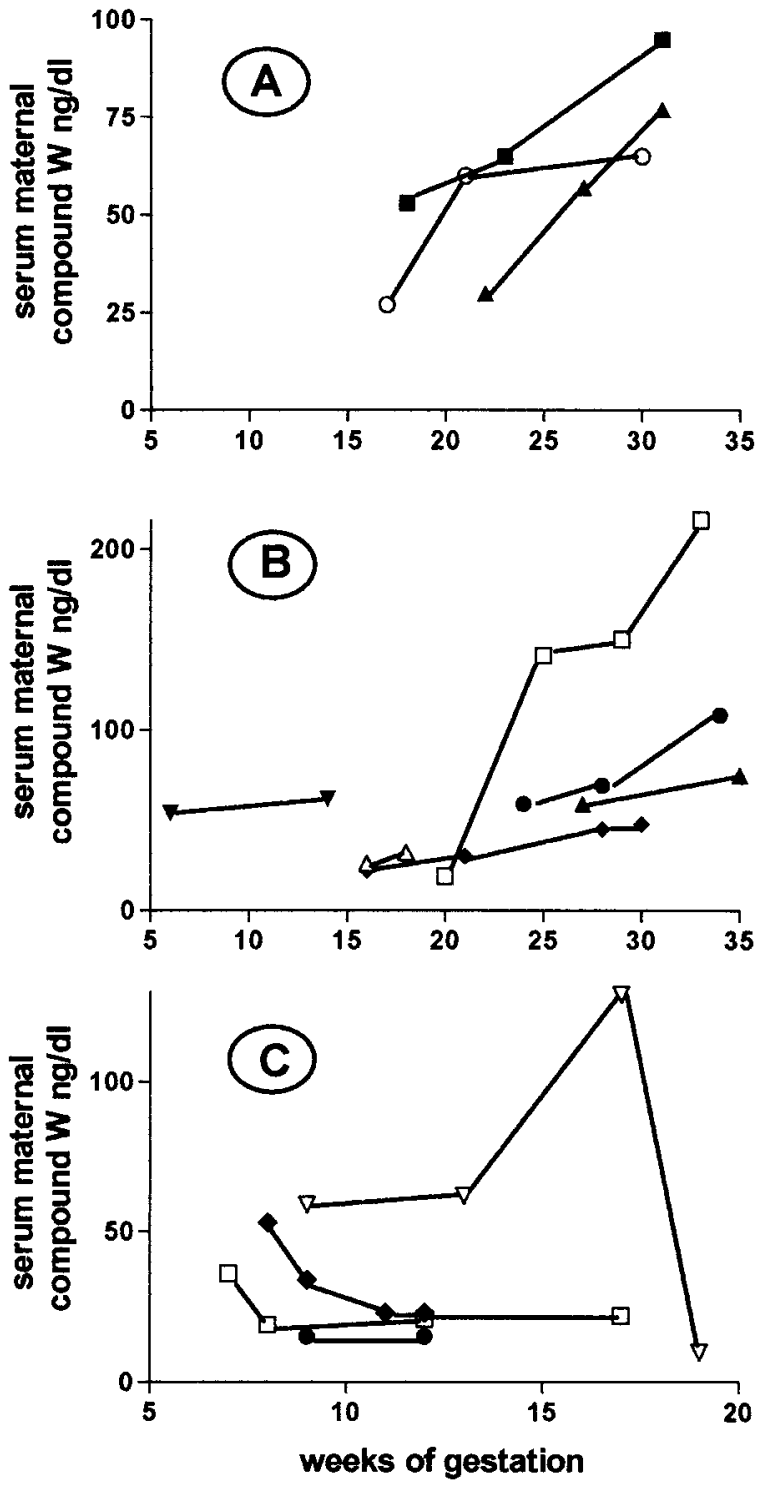

no information on fetal thyroid function could be obtained.

\section{Transplacental passage of TRIAC}

Forty-six to $76 \mathrm{~min}$ after TRIAC administration, FT3 concentrations were extremely elevated in both the maternal and fetal circulation (Table 2). In fact, the maximum FT3 level recorded in 70 normal fetuses at that gestational age was $3.1 \mathrm{pmol} / \mathrm{l}$, indicating a clear transplacental passage of the analog. In all fetuses, TSH and FT4 levels were within the normal range with one exception, a patient (no. 3, Table 2) who was hypothyroid (TSH: $19.6 \mathrm{mU} / \mathrm{l})$. In this fetus, the recorded FT3 levels were the highest observed $(18.8 \mathrm{pmol} / \mathrm{l})$. In contrast, no transplacental passage of $\mathrm{T} 3$ was observed during T3 administration, although FT3 levels in the mothers increased by 4- to 10-fold (Table 2). During both TRIAC and T3 administration, maternal TSH levels decreased, while FT4 did not vary significantly. No adverse reaction was observed in any woman.

\section{Compound $W$ concentrations in three hyperthyroid pregnant women treated with PTU}

The first patient (Fig. 6A) started therapy with $100 \mathrm{mg}$ of PTU/day and the dosage was increased to $300 \mathrm{mg} /$ day because of the marked thyrotoxicosis; the dose was subsequently reduced to $100 \mathrm{mg} /$ day and finally $50 \mathrm{mg} /$ day until the end of pregnancy. At 28 weeks of gestation, a cordocentesis revealed fetal hypothyroidism (fetal TSH: $66.9 \mathrm{mU} / \mathrm{l}, \mathrm{FT} 4: 8.3 \mathrm{pmol} / \mathrm{l}$ ) and the ultrasound scan

Figure 5 Serial measurement of serum compound $W$ in three pregnant women without thyroid disorders $(A)$, in six hypothyroid pregnant women treated with substitutive doses of L-T4 (B) and in four hyperthyroid pregnant PTU-treated women (C). One patient (open triangles) discontinued PTU therapy at 14 weeks of gestation for unknown reasons; in that period compound W levels remarkably increased, but declined when PTU therapy was reestablished. 
Table 2 Effects of administration of TRIAC $(3.5 \mathrm{mg})$ or T3 $(200 \mu \mathrm{g})$ to the mother on both maternal and fetal TSH and thyroid hormone levels.

\begin{tabular}{|c|c|c|c|c|c|c|c|}
\hline \multirow[b]{2}{*}{$\begin{array}{l}\text { Patient } \\
\text { no. }\end{array}$} & \multirow[b]{2}{*}{$\begin{array}{l}\text { Time } \\
(\min )\end{array}$} & \multicolumn{3}{|c|}{ Mother } & \multicolumn{3}{|c|}{ Fetus } \\
\hline & & $\begin{array}{c}\text { TSH } \\
(\mathrm{mU} / \mathrm{l})\end{array}$ & $\begin{array}{c}\text { FT4 } \\
(\mathrm{pmol} / \mathrm{l})\end{array}$ & $\begin{array}{c}\text { FT3/TRIAC } \\
(\mathrm{pmol} / \mathrm{l})\end{array}$ & $\begin{array}{l}\text { TSH } \\
(\mathrm{mU} / \mathrm{l})\end{array}$ & $\begin{array}{c}\text { FT4 } \\
(\text { pmol/l) }\end{array}$ & $\begin{array}{c}\text { FT3/TRIAC } \\
(\mathrm{pmol} / \mathrm{l})\end{array}$ \\
\hline 1 & 0 & 1.3 & 10.7 & 4.3 & - & - & - \\
\hline (TRIAC) & 76 & 0.9 & 10.0 & $>75$ & 4.7 & 9.7 & 5.2 \\
\hline 2 & 0 & 1.1 & 9.4 & 4.1 & - & - & - \\
\hline (TRIAC) & 48 & 0.9 & 10.2 & $>75$ & 3.3 & 13.6 & 8.0 \\
\hline 3 & 0 & 1.2 & 9.1 & 5.6 & - & - & - \\
\hline (TRIAC) & 60 & 1.0 & 8.5 & $>75$ & 19.6 & 7.9 & 18.8 \\
\hline 4 & 0 & 3.4 & 8.5 & 3.5 & - & - & - \\
\hline (TRIAC) & 53 & 2.3 & 9.5 & $>75$ & 8.3 & 12.3 & 4.9 \\
\hline 5 & 0 & 0.9 & 10.9 & 4.6 & - & - & - \\
\hline (T3) & 53 & 0.6 & 11.4 & 46.5 & 5.0 & 10.6 & 2.0 \\
\hline 6 & 0 & 1.6 & 10.1 & 4.0 & - & - & - \\
\hline (T3) & 46 & 1.5 & 11.0 & 16.3 & 6.4 & 8.6 & 0.5 \\
\hline
\end{tabular}

indicated an associated fetal goiter (fetal thyroid width: $28 \mathrm{~mm}$ vs $15.2-18.1 \mathrm{~mm}$ in controls) (24). The fetal compound $\mathrm{W}$ level at 32 weeks of gestation was clearly low (64 vs $94-260 \mathrm{ng} / \mathrm{dl}$ as range for the same period) (Table 1), whereas at term the value had increased to $150 \mathrm{ng} / \mathrm{dl}$ (range at 37-40 week of gestation: 124$200 \mathrm{ng} / \mathrm{dl})$. Compound $\mathrm{W}$ in maternal serum was within the normal range for gestational age, but did not show the usual progressive increase expected at that period of pregnancy. Compound $\mathrm{W}$ levels increased only after 30 weeks of gestation when the PTU dose was reduced to $50 \mathrm{mg} /$ day.
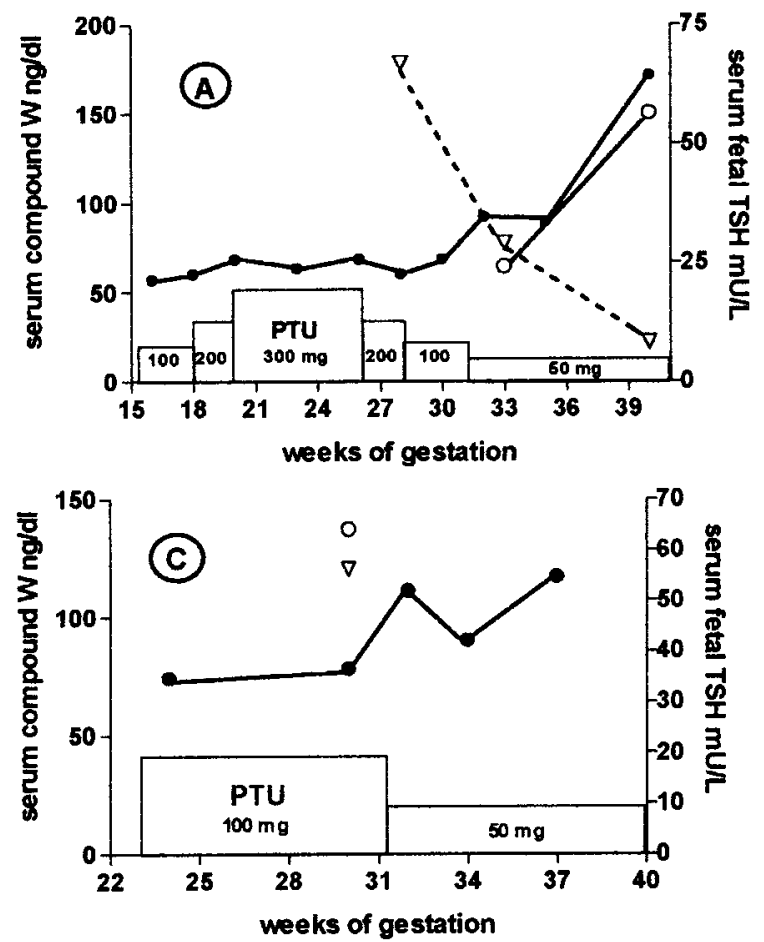

Figure 6 Levels of fetal and maternal compound W and fetal TSH in three hyperthyroid mothers treated with PTU (A, B and C respectively).
The second patient (Fig. 6B) was treated at 6 weeks of gestation with $300 \mathrm{mg} /$ day of PTU. Because of the severity of hyperthyroidism, this dose was continued until 14 weeks, at which time it was possible to reduce the dose of PTU to $200 \mathrm{mg} /$ day and then to $100 \mathrm{mg} /$ day. At 19 weeks of gestation, a cordocentesis was carried out because of a coexisting hematological disorder (thalassemia minor in both parents). Thalassemia major was excluded, but the fetal TSH levels were elevated $(35.8 \mathrm{mU} / \mathrm{l})$. There was no fetal goiter. Fetal compound $\mathrm{W}$ was normal, though maternal compound W (36 ng/ dl) was in the low normal range at 19 weeks (range at
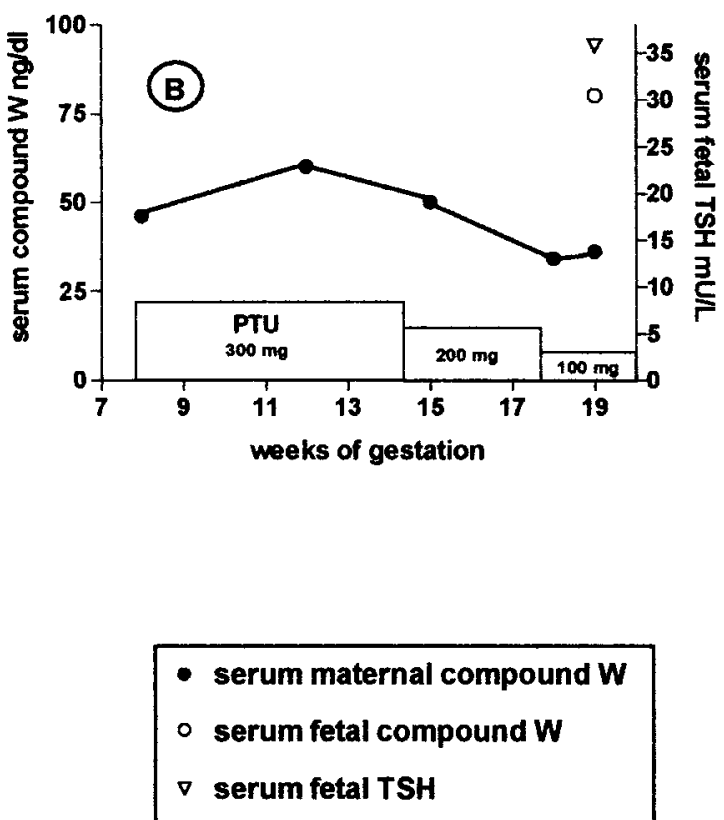


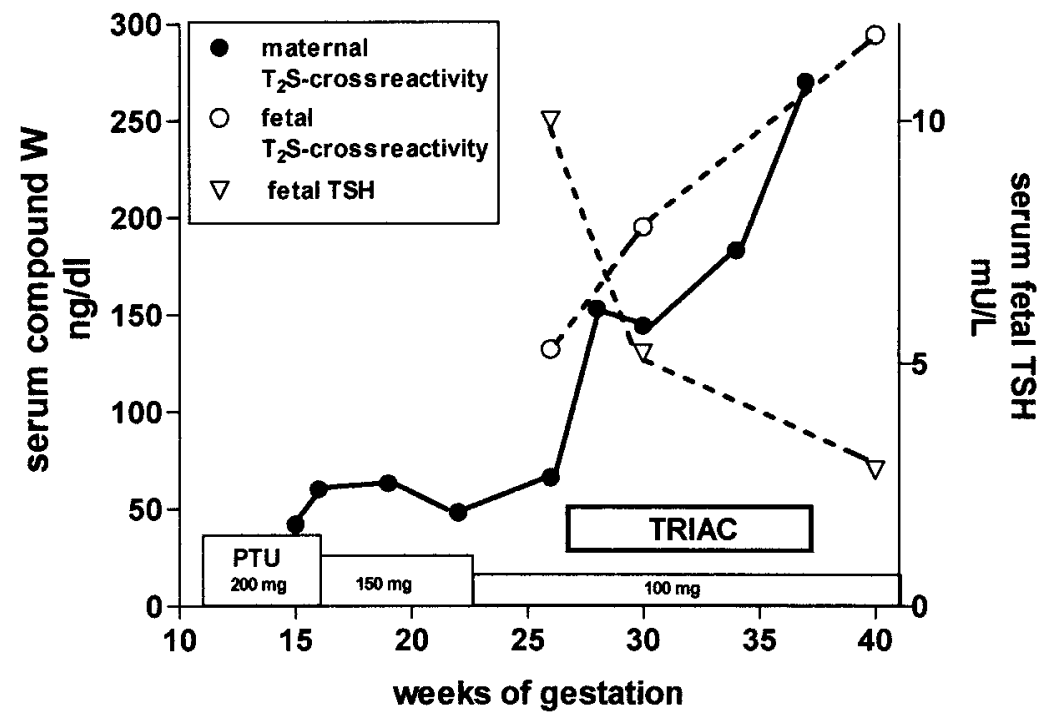

Figure 7 Levels of fetal and maternal T2S crossreactivity (compound W and 3,3'-DIACS) and fetal TSH in a hyperthyroid mother treated with PTU at different doses and TRIAC (2.1$2.8 \mathrm{mg} /$ day orally from 26 weeks of gestation until term).
14-20 weeks of gestation: $27-138 \mathrm{ng} / \mathrm{ml}$ ). The patient dropped out of the study at 20 weeks of gestation for unknown reasons.

In the third case (Fig. 6C) the patient started therapy with PTU $200 \mathrm{mg}$ /day and at 20 weeks of gestation the dose was reduced to $100 \mathrm{mg} /$ day. At 30 weeks a cordocentesis revealed an elevated fetal TSH $(56.2 \mathrm{mU} / \mathrm{l})$. There was no goiter. The patient was clinically euthyroid, so it was possible to further decrease the dose of PTU ( $50 \mathrm{mg} /$ day). Fetal compound $\mathrm{W}$ levels were normal and serial measurements in the mother revealed that maternal compound $\mathrm{W}$ increased only after the PTU dose was reduced to $50 \mathrm{mg} /$ day.

\section{Compound $W$ concentrations in one hyperthyroid pregnant woman treated with PTU and TRIAC}

Figure 7 summarizes data for the woman treated with combined PTU (200 mg/day at the 15 th week and then $100 \mathrm{mg} /$ day until term) and TRIAC (2.1-2.8 mg/day orally from the 26 th week until term). This therapy was provided because of fetal goiter (fetal thyroid width: $32 \mathrm{~mm}$ vs $12.2-15.1 \mathrm{~mm}$ in euthyroid controls) (24) and mild fetal hypothyroidism, documented by mildly elevated serum TSH levels (10.0 mU/l) and low FT4 levels (3.1 pmol/l; reference range for 90 fetuses at 24-27 weeks of gestation: $8.6-19.5 \mathrm{pmol} / \mathrm{l})$. Serial measurements of maternal compound $\mathrm{W}$ were within the normal range, but without the usual increase expected during the second trimester. At 26 weeks of gestation, when the first cordocentesis was carried out, fetal compound $\mathrm{W}$ levels also were normal. After 15 days of TRIAC treatment, fetal TSH levels decreased and an ultrasound scan revealed shrinking of the fetal goiter (thyroid width: $20 \mathrm{~mm}$ vs $15.2-18.1$ ) (24). Successive fetal and maternal compound $\mathrm{W}$ measurements increased progressively and markedly after 30 weeks reaching values of $250-300 \mathrm{ng} / \mathrm{dl}$. These measurements reflect the combined crossreactivity of 3,3'-DIACS and fetal compound W. TRIAC was not associated with untoward maternal effects, and after spontaneous onset of labor at 39 weeks of gestation, the patient delivered a female neonate who is now healthy and neurologically normal at 20 months of age.

\section{Discussion}

The present studies were undertaken to evaluate the possible use of compound $\mathrm{W}$ as a maternal marker of fetal thyroid dysfunction. An earlier report suggested that compound $\mathrm{W}$, a T2S-like immunoreactive material present in maternal and fetal serum during pregnancy, is a thyroid hormone sulfoconjugate (5).

Our results suggest strongly that compound $\mathrm{W}$ is a metabolite of fetal thyroid hormone capable of transplacental fetal to maternal transfer. In fact, both maternal and fetal compound $\mathrm{W}$ levels increase progressively during gestation with significant direct correlation. Additionally, a positive correlation was observed between fetal compound W and fetal FT4, whereas no correlation was observed between maternal compound $\mathrm{W}$ and maternal FT4. Maternal compound W levels seem to reflect the effects of drugs on fetal thyroid function. In women on PTU, maternal compound W levels were in the low normal range, and did not show the usual increase with progression of gestation from the 2nd to 3rd trimester. A significant increase in maternal compound $\mathrm{W}$ was observed when the PTU dose was decreased to $50 \mathrm{mg} /$ day, or was discontinued. Furthermore, we found that compound W levels were in the normal range also in the two women with goiter treated with L-T4 therapy at TSH-suppressive doses, supporting the view that such therapy (for the prevention of the increase of maternal goiter) is completely safe for the fetus. 
Serial measurements of compound $\mathrm{W}$ in maternal serum can be considered a safe and practical test for the assessment of fetal thyroid function, particularly in hyperthyroid women treated with anti-thyroid drugs, whose fetuses could become hypothyroid due to the transplacental passage of the drug. Presently, the most precise way to diagnose fetal hypothyroidism is to perform cordocentesis and measure fetal TSH and FT4. However, this is an invasive procedure, associated with $1 \%$ fetal loss (12). However, this approach allows the early diagnosis of fetal hypothyroidism and the provision of substitutive therapy in utero $(25,26)$. Several recent studies have shown that intrauterine hypothyroidism is associated with decreased IQ values at 3-7 years even if a correct neonatal thyroid hormone replacement therapy is provided $(27-32)$.

Since limited amounts of iodothyronines cross the placenta (33-36), administration of $\mathrm{T} 4$ or $\mathrm{T} 3$ to the mother is of limited value for therapy of fetal hypothyroidism and carries the risk of worsening of maternal hyperthyroidism. The amount of maternal hormone reaching the fetus in cases of severe fetal hypothyroidism appears insufficient to prevent the fetal pathology (36-38). Direct fetal therapy is now possible by periodic insertion of L-T4 into the amniotic fluid, at doses ranging from 120 to $500 \mu \mathrm{g}$, with intervals between intra-amniotic injection of 1 or 2 weeks $(26,39)$. One disadvantage of this technique is that it requires multiple invasive procedures. Another alternative is maternal TRIAC therapy $(15,40)$. Our results on transplacental passage of TRIAC confirm that TRIAC administered to the mother does cross the placenta. In fact, in the fetuses whose mothers received TRIAC, FT3 levels were 1.6- to 6-fold higher than the upper limit of the reference range $(2,41)$. Due to the $100 \%$ crossreaction with TRIAC of anti-T3 antibodies employed in our FT3 measurement method, this finding confirms the transplacental passage of the analog. Interestingly enough, the transplacental passage of TRIAC was highest in the only fetus who appeared to be hypothyroid, as documented by high circulating TSH levels. T3 given to the two pregnant women did not cross the placenta as documented by the low FT3 levels in fetal circulation.

These very limited studies suggest the possible benefits of TRIAC in the prevention of fetal hypothyroxinemia and goiter. We attempted this alternative therapy in one of the two hyperthyroid women on PTU and complicated by fetal hypothyroidism and goiter. Our study shows that TRIAC was effective in decreasing fetal TSH concentrations and fetal goiter size without invasive procedures. The mother showed no untoward consequences and the neonate was clinically euthyroid, and her somatic and neurological development was completely normal at the age of 24 months. However, further studies are necessary before using TRIAC as a routine procedure. In fact, data from animal studies suggest that $\mathrm{T} 3$ treatment of hypothyroid pregnant rats is potentially hazardous for fetal brain protection (42).
Nonetheless, circulating FT4 levels in our pregnant patient were constantly normal during PTU and TRIAC treatment.

Increases in maternal serum 3,3'-T2S have been shown in maternal sheep after T3-infusion into fetal lambs (43). Thus, it is likely that 3,3'-DIACS would be present in maternal serum of pregnant women treated with TRIAC. Indeed, this was the case. Interestingly, the 3,3'-T2S RIA could also be used to measure serum levels of 3,3'-DIACS even though the HPLC retention times of the 3,3'-T2S and 3,3'-DIACS are quite different. The exact crossreactivity of 3,3'-DIACS in 3,3'-T2S RIA is not clear. However, in view of the $100 \%$ crossreactivity of TRIAC in T3 RIA, the crossreactivity of 3,3'-DIACS in 3,3'-T2S RIA should be substantial. One may question whether the $3,3^{\prime}$-DIACS is produced in the fetal or in the maternal compartment. It is presumed that this sulfated DIAC is produced in the fetal or placental compartment and transported back into maternal serum, a process similar to the metabolism of T2S in sheep (43) and compound W in humans $(5,6)$. Further study in non-pregnant women or in the thyroid hormone resistance syndrome patients who are treated with similar doses of TRIAC (44) would shed light on the origin of DIACS.

In conclusion, our data suggest that a random compound $\mathrm{W}$ measurement as a pregnant population screening may not be conclusive, whereas longitudinal evaluation of compound $W$ appears to be a useful parameter of fetal thyroid function. Nevertheless, serial measurements of 3,3'-T2S crossreactive materials (compound W and 3,3'-DIACS) in maternal blood and the administration of TRIAC to the mother may represent a useful and safe alternative to invasive techniques for the diagnosis and therapy of fetal hypothyroidism.

\section{References}

1 Wu SY, Polk H, Wong S, Reviczky A, Vu R \& Fisher DA. Thyronine sulfate is a major thyroid hormone metabolite and a potential intermediate in the monodeiodination pathways in fetal sheep. Endocrinology 1992131 1751-1756.

2 Santini F, Cortelazzi D, Baggiani AM, Marconi AM, Beck-Peccoz P \& Chopra IJ. A study of the serum 3,5,3' triiodothyronine sulfate concentration in normal and hypothyroid fetuses at various gestational stages. Journal of Clinical Endocrinology and Metabolism 199376 1583-1587.

3 Polk DH, Wu SY, Huang WS \& Reviczky A. Metabolism of sulfoconjugated thyroid hormone derivatives in developing sheep. American Journal of Physiology 1994266 E892-E896.

4 Wu SY, Huang WS, Polk D, Florsheim WH, Green WL \& Fisher DA. Identification of thyroxine-sulfate (T4S) in human serum and amniotic fluid by a novel T4S radioimmunoassay. Thyroid 19922 101-105.

5 Wu SY, Polk DH, Chen WL, Fisher DA, Huang WS \& Yee B. A 3,3'Diiodothyronine sulfate cross-reactive compound in serum from pregnant women. Journal of Clinical Endocrinology and Metabolism 199478 1505-1508.

6 Wu SY, Fisher DA, Huang WS, Beck-Peccoz P, Emerson CH, Kuo SW et al. Urinary compound $\mathrm{W}$ in pregnant women is a potential marker for fetal thyroid function. American Journal of Obstetrics and Gynecologyy 1998178 886-897. 
7 Fisher DA \& Klein AH. Thyroid development and disorders of thyroid function in the newborn. New England Journal of Medicine $1981304702-712$

8 Landau H, Sack J, Frucht H, Palti Z, Hochner-Celnikier D \& Rosenmann A. Amniotic fluid 3,3',5'-triiodothyronine in the detection of congenital hypothyroidism. Journal of Clinical Endocrinology and Metabolism 198050 799-801.

9 El Zahari MM, Vagenakis AG, Hinerfeld L, Emerson $\mathrm{CH}$ \& Braverman LE. Maternal thyroid function is the major determinant of amniotic fluid 3,3',5'-triiodothyronine in the rat. Journal of Clinical Investigation 198167 1126-1133.

10 Bachrach LK \& Burrow GN. Thyroid function in pregnancy. In Pediatric Thyroidology, pp 1-18. Eds F Delange, DA Fisher \& P Malvaux. Basel: Karger, 1985.

11 Emerson $\mathrm{CH}$. Thyroid disease during and after pregnancy. In Werner and Ingbar's The Thyroid, edn 7, pp 1025. Eds LE Braverman \& RD Utiger. Philadelphia: Lippincott, 1991.

12 Daffos F, Cappella-Pavlovsky M \& Forestier F. A new procedure for fetal blood sampling in utero: preliminary results of fifty three cases. American Journal of Obstetrics and Gynecology 1983146 985-987.

13 Cheron RG, Kapland MM, Larsen PR, Selenkow HA \& Crigler JFJ. Neonatal thyroid function after propylthiouracil therapy for maternal Graves' disease. New England Journal of Medicine 1981 $304525-528$

14 Fuggle PW, Grant DB, Smith I \& Murphy G. Intelligence, motor skills and behaviour at 5 years in early-treated congenital hypothyroidism. European Journal of Pediatrics 1991150 570-574.

15 Nicolini U, Venegoni E, Acaia B, Cortelazzi D \& Beck-Peccoz P. Prenatal hypothyroidism: is there more than one option? Prenatal Diagnosis. $199616443-448$.

16 Gavin LA, Livermore BM, Cavalieri RR, Hammond ME \& Castle JN. Serum concentration, metabolic clearance, and production rate of 3,5,3'-triiodothyroacetic acid in normal and athyreotic man. Journal of Clinical Endocrinology and Metabolism 198051529 534.

17 Takeda T, Suzuki S, Liu RT \& DeGroot LJ. Triiodothyroacetic acid has unique potential for therapy of resistance to thyroid hormone. Journal of Clinical Endocrinology and Metabolism 1995802033 2040.

18 Goslings B, Schwartz HL, Dillman W, Surks MI \& Oppenheimer JH. Comparison of the metabolism and distribution of L-triiodothyronine and triiodothyroacetic acid in the rat: a possible explanation of differential hormonal potency. Endocrinology 1976 98 666-671.

19 Beck-Peccoz P, Sartorio A, De Medici C, Grugni G, Morabito F \& Faglia G. Dissociated thyromimetic effects of 3,5,3'-triiodothyroacetic acid (TRIAC) at the pituitary and peripheral tissue levels Journal of Endocrinological Investigation 19811 113-118.

20 Pardi G, Cetin I, Marconi AM, Lanfranchi A, Bozzetti P, Ferrazzi E et al. Diagnostic value of blood sampling in fetuses with growth retardation. New England Journal of Medicine $1993328692-696$.

21 Eelkman-Rooda SJ, Kaptein E, Van Loon MAC \& Visser TJ. Development of a radioimmunoassay for triiodothyronine sulfate. Journal of Immunoassay 19889 125-134.

22 Mol JA \& Visser TJ. Synthesis and some properties of sulfate esters and sulfamates of iodothyronines. Endocrinology $19851171-7$.

23 Wu SY, Chopra IJ, Nakamura Y, Soloman DH \& Bennet LR. A radioimmunoassay for measurement of 3,3'-L-diiodothyronine (T2). Journal of Clinical Endocrinology and Metabolism 197643 $682-685$.

24 Achiron R, Rotstein Z, Lipitz S, Karasik A \& Seidman DS. The development of the foetal thyroid: in utero ultrasonographic measurements. Clinical Endocrinology 199848 259-264.

25 Perelman AH, Johnson RL, Clemons RD, Finber HJ, Clewell WH \& Trujillo L. Intrauerine diagnosis and treatment of fetal goitrous hypothyroidism. Journal of Clinical Endocrinology and Metabolism $199071618-621$

26 Abhamad AZ, Fisher DA, Warsaf SL, Slotnick RN, Pyle PG \& Wu SY. Antenatal diagnosis and treatment of fetal goitrous hypothyroidism: case report and review of literature. Ultrasound in Obstetrics and Gynecology 19956 368-371.

27 Glorieux J, Dussault JH, Marisette J, Desjardins M, Letarte J \& Guyda H. Follow-up of ages 5 and 7 years on mental development in children with hypothyroidism detected by Quebec screening program. Journal of Pediatrics 1988107 913-915.

28 Porterfield SP \& Hendrich CE. The role of thyroid hormones in prenatal and neonatal neurological development - current perspectives. Endocrine Reviews 199314 94-106.

29 La Franchi S. Recent developments in pediatric thyroidology. Thyroid Today 199821 1-13.

30 Kooistra L, Van der Meere JJ, Vulsma T \& Kalverboer AF. Sustained attention problems in children with early congenital hypothyroidism. Acta Pediatrica 199685 425-429.

31 Peter F, Muszsnai A \& Szigetvari A. Intellectual assessment of hypothyroid children detected by screening. Acta Medica Austriaca $19921960-61$

32 Calaciura F, Mendorla G, Distefano M, Castorina S, Fazio T, Motta RM et al. Childhood IQ measurements in infants with transient congenital hypothyroidism. Clinical Endocrinology $199543473-$ 477.

33 Morreale de Escobar G, Obregòn MJ, Calvo R \& Escobar del Rey F. Effects of iodine deficiency on thyroid hormone metabolism and the brain in fetal rats: the role of the maternal transfer of thyroxine. American Journal of Clinical Nutrition 199357 (Suppl 2) 280-285.

34 Mortimer RH, Galligan JP, Cannell GR, Addison RS \& Roberts MS. Maternal to fetal thyroxine transmission in the human term placenta is limited by inner ring deiodination. Journal of Clinical Endocrinology and Metabolism 199681 2247-2249.

35 Castro MI, Braverman LE, Alex S, Wu CF \& Emerson CH. Innerring deiodination of 3,5,3'-triiodothyronine in the in situ perfused guinea pig placenta. Journal of Clinical Investigation 198576 1921-1926.

36 Vulsma T, Gons MH \& De Vijlder JJM. Maternal-fetal transfer of thyroxine in congenital hypothyroidism due to a total organification defect on thyroid agenesis. New England Journal of Medicine $198932113-16$

37 Sack J, Kaiserman I \& Siebner R. Maternal-fetal T4 transfer does not suffice to prevent the effect of in utero hypothyroidism. Hormone Research 199339 1-7.

38 Fisher DA. Fetal thyroid function: diagnosis and management of fetal thyroid disorders. Clinical Obstetrics and Gynecology 199740 $16-31$.

39 Van Loon AJ, Derkesen JT, Bos AF \& Rouwé CW. In utero diagnosis and treatment of fetal goitrous hypothyroidism, caused by maternal use of propylthiouracil. Prenatal Diagnosis 199515 599-604.

40 Asteria C, Rajanayagam O, Collingwood TN, Persani L, Romoli R, Mannavola D et al. Prenatal diagnosis of thyroid hormone resistance. Journal of Clinical Endocrinology and Metabolism 1999 84 405-410.

41 Thorpe-Beeston JG, Nicolaides KH, Butler J, Felton CV \& McGregor AM. Maturation of the secretion of thyroid hormone and thyroidstimulating hormone in the fetus. New England Journal of Medicine $1991324532-536$.

42 Calvo R, Obregòn MJ, Ruiz de Ona C, Escobar del Rey F \& Morreale de Escobar G. Congenital hypothyroidism, as studied in rats. Journal of Clinical Investigation 199086 889-899.

43 Wu SY, Polk DH, Fisher DA, Huang WS, Reviczky AL \& Chen WL. Identification of 3,3'-diiodothyronine sulfate $\left(3,3^{\prime}-\mathrm{T} 2 \mathrm{~S}\right)$ as a fetal thyroid hormone derivative in maternal urine in sheep. American Journal of Physiology 1995268 E33-E39.

44 Beck-Peccoz P, Asteria C \& Mannavola D. Resistance to thyroid hormone. In Contemporary Endocrinology: Disease of the Thyroid, pp 199-239. Ed. LE Braverman. Totowa, NJ: Humana Press, 1997.

Received 15 December 1998

Accepted 18 August 1999 